\title{
Colonization success of common Thai mangrove species as a function of shelter from water movement
}

\author{
Udomluck Thampanya ${ }^{1}$, Jan E. Vermaat ${ }^{2, *}$, Carlos M. Duarte ${ }^{3}$ \\ ${ }^{1}$ Coastal Resources Institute, Prince of Songkla University, Hat Yai, Songkhla 90112, Thailand \\ ${ }^{2}$ International Institute for Infrastructural, Hydraulic and Environmental Engineering, Delft, The Netherlands \\ ${ }^{3}$ IMEDEA (CSIC-UIB), Instituto Mediterráneo de Estudios Avanzados, CSIC-Universidad, Illes Balears, C/Miguel Margués 21, \\ 07190 Esporles, Mallorca, Spain
}

\begin{abstract}
Seedling survival and growth of the 3 common SE Asian mangrove species Avicennia alba, Rhizophora mucronata and Sonneratia caseolaris were quantified experimentally along 2 spatial gradients of shelter: (1) between 2 stations, at the inner and outer end of the sheltered Pak Phanang Bay (SW Thailand); and (2) for each station, among plots across a gradient of vegetation density from the mangrove forest edge inwards. Exposure to water movement, quantified as gypsum clod card weight loss, was found to vary more than 5-fold between seasons, which contributed most of the variance accounted for $(73 \%)$. Variation between plots was higher than that between the 2 stations: clod card loss ranged between 3.0 and $4.6 \mathrm{~g} \mathrm{~d}^{-1}$ in the plots, whereas the grand means of the 2 stations were 3.4 and $3.7 \mathrm{~g} \mathrm{~d}^{-1}$, respectively. These differences between stations and plots were comparable to the patterns found for mangrove seedling survival. Survival was high (80 to $93 \%$ ) in most treatments in $R$. mucronata, with the exception of the most exposed plot (30\%). In the other 2 species, overall survival was significantly less but was highest in the outermost plots with the lowest tree density. This pattern confirms the successional status of these 3 mangrove species. Seedling growth, expressed as height increase, was significantly reduced with increasing neighboring tree density for $A$. alba and $S$. caseolaris, whereas $R$. mucronata showed an opposite pattern. Internode production of all 3 species was highest in the most exposed plots. Overall, relative growth rate, expressed as height increase, declined with the age of the seedlings.
\end{abstract}

KEY WORDS: Mangrove $\cdot$ Seedlings $\cdot$ Exposure $\cdot$ Water movement $\cdot$ Clod card $\cdot$ SE Asia

Resale or republication not permitted without written consent of the publisher

\section{INTRODUCTION}

Seedling establishment is a critical stage in the life cycle of most angiosperms (Silvertown 1982). The advanced developmental stage of viviparous mangrove seedlings, which develop while still attached to the mother tree in the Rhizophoreae genera, is generally interpreted to be adaptive (Tomlinson 1986) and to facilitate rapid establishment through rooting (Hutch-

${ }^{*}$ Corresponding author. Present address: Institute for Environmental Studies, Vrije Universiteit, De Boelelaan 1087, 1081 HV Amsterdam, The Netherlands.

E-mail: jan.vermaat@ivm.vu.nl ings \& Saenger 1987). After a period of positive buoyancy, dispersed propagules sink or become stranded, and successful rooting is the first step toward seedling establishment (Hutchings \& Saenger 1987, Tomlinson 2000). However, establishment may be hindered by tidal current and wave buffeting (Clarke 1995) or lack of shelter from water movement (Clough 1982). Consequently, large proportions (as high as $90 \%$ ) of already rooted seedlings may fail to become fully established (Delgado et al. 1999). Furthermore, post-establishment mortality during the first year is considerable: Hutchings \& Saenger (1987) reported 22, 36 and $72 \%$ mortality in the first year for Avicennia sp., Ceriops sp., and Rhizophora stylosa, respectively. In this stage, possible 
mortality sources include herbivory, drought or salinity stress, insufficient light, damage from drifting objects and strong water movement (Hutchings \& Saenger 1987, Clarke 1995). Published relevant quantitative data on mangrove seedling survival and sources of mortality, however, are scarce (Hutchings \& Saenger 1987, Clarke \& Allaway 1993).

Our aim was to assess the effect of seasonal variation in exposure to water movement on the survival and growth of seedlings of 3 common SE Asian mangrove species at 2 spatial scales: (1) at a larger scale along a gradient from the river mouth to the sea in an enclosed bay (Pak Phanang Bay, Southern Thailand); and (2) at a smaller scale along a gradient of neighboring plant density from the edge of an expanding mangrove forest perpendicular into the forest. In addition to their interest in providing information on factors affecting the early success of mangrove seedlings, the goals set here are important to the design of successful largescale mangrove rehabilitation schemes, such as those carried out at present in Thailand and neighboring countries (Field 1995, Havanond 1995).

\section{MATERIALS AND METHODS}

Study area. Pak Phanang Bay ( $\left.8^{\circ} 25.11^{\prime} \mathrm{N}, 100^{\circ} 09.18^{\prime} \mathrm{E}\right)$ is a large, shallow bay, sheltered from the Gulf of Thailand by a long northwest-pointing sandbar (Fig. 1). The eastern side of the bay is largely occupied by mangrove forest with an area of approximately $90 \mathrm{~km}^{2}$. The Pak
Phanang River, $110 \mathrm{~km}$ long, discharges into the bay from the south. Tides are mixed diurnal and ranged between 0.1 and $0.7 \mathrm{~m}$ in August 1998, and between 0.7 and $1.3 \mathrm{~m}$ above the lowest low tide level in January 1999. Published average velocities are $0.6 \mathrm{~m} \mathrm{~s}^{-1}$ for ebb currents and $0.8 \mathrm{~m} \mathrm{~s}^{-1}$ for flood currents (JICA 1987). Annually, the area experiences 3 distinct seasons: hotdry season (February to May), rainy season (June to September) and the highest rainfall period of monsoon season (October to January; Fig. 2), with an average annual rainfall of $2400 \mathrm{~mm}$. The mean air temperature is $28^{\circ} \mathrm{C}$ and the water temperature ranges between 25 and $36^{\circ} \mathrm{C}$. The experiment was conducted at the bayside edge of the mangrove forest. Two stations with different exposure were selected: Stn 1, at the mouth of Pak Kwang Canal near the river mouth, and Stn 2, at the mouth of Ai Ho Canal $5 \mathrm{~km}$ away from Stn 1. At each station, 3 plots of $10 \mathrm{~m} \times 30 \mathrm{~m}$ were set up at different densities of naturally occurring, neighboring plants: low, medium and high (Table 1). The 3 plots of Stn 1 were mostly occupied by Sonneratia caseolaris trees ( 2 to $5 \mathrm{~m}$ in height), saplings and seedlings with a few Avicennia spp. (A. alba and A. officinalis) saplings and seedlings, while all the plots of Stn 2 were occupied by Avicennia sp. trees, saplings and seedlings. The upper areas and hinterland are occupied by planted $R h i-$ zophora apiculata and Rhizophora mucronata (5 to $20 \mathrm{~m}$ in height). Soil textures of both stations are silty clay (53\% clay for Stn 1 and $56 \%$ clay for Stn 2 ), and the substrate surface is relatively flat $(+1 \mathrm{~m}$ elevation above mean sea level for both stations).

Measurement of water movement and other environmental parameters. The dimensionless water movement was quantified using the dissolution rate of clod cards (Doty 1971, Jokiel \& Morrissey 1993). This inexpensive and practical method quantifies weight loss of a sparingly soluble substance such as plaster of Paris or gypsum. Reportedly, weight loss is directly related to water motion (Petticrew \& Kalff 1991, Jokiel \& Morrissey 1993, but see Porter et al. 2000 for a critical assessment). A large number of plaster of Paris clods of considerable size (30 to $40 \mathrm{~g}$ ) were produced using ice-cube trays as templates and allowed to air-dry at room temperature $\left(28\right.$ to $33^{\circ} \mathrm{C}$ ) for $1 \mathrm{wk}$ to reach constant weight. Thereafter, each clod was glued to a card of $5 \mathrm{~cm} \times 7 \mathrm{~cm}$ rubber floor cover. After being oven-dried at $60^{\circ} \mathrm{C}$ for $24 \mathrm{~h}$, the clod cards were preweighed before deployment. At the study site, each pair of clod cards was attached, using rubber elastic rings, to a piece $(8 \mathrm{~cm} \times$ $16 \mathrm{~cm}$ ) of thin board with a hole punched in

Fig. 1. Map of Pak Phanang Bay, southern Thailand, showing the 2 stations. A: Ai Ho; P: Pak Kwang 
the middle. Fifteen pairs of clod cards were deployed randomly in each plot at both stations. The clod card set was fixed to the substrate with a stick. After being deployed for $24 \mathrm{~h}$, the clod cards were collected and carefully carried back to the laboratory. Subsequently, they were allowed to air-dry for a week and were re-weighed after drying at $60^{\circ} \mathrm{C}$ for $24 \mathrm{~h}$. Clod cards were deployed randomly in the diel and monthly (lunar) tidal cycle: low tide occurred at 15, 18, 8, 8, 23, 5 and $22 \mathrm{~h}$, respectively, on subsequent days of deployment.

Data were analyzed using an ANOVAgeneral linear model (GLM) full factorial model comparing weight loss per day between seasons, stations and plots. Closed boxes (15 l) containing control clod cards were also deployed in situ,

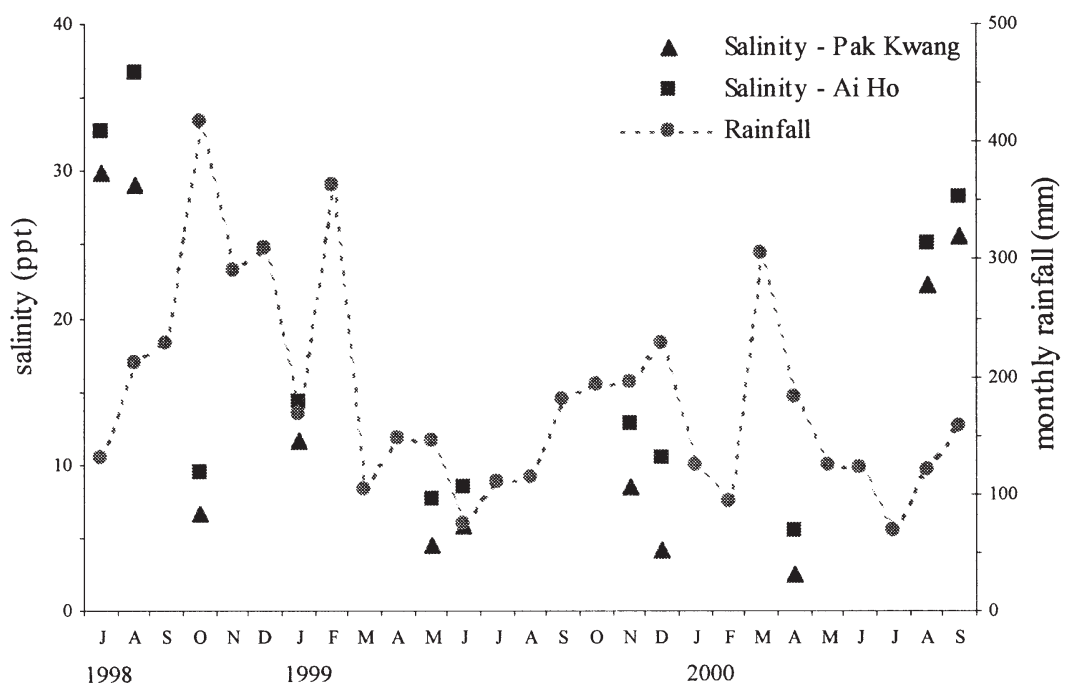

Fig. 2. Salinity (\%o) measured at the 2 stations and mean monthly rainfall (mm) calculated from the meteorological stations adjacent to Pak Phanang Bay allowing the calculation of the diffusion factor (DF), sensu Jokiel \& Morrissey (1993), as weight loss in situ/weight loss in still water. Salinity was measured in situ with a Wissenschaftlich Technische Werkstätte conductivity meter. Rainfall data were obtained from the meteorological stations surrounding the study area.

Seedling survival and growth. Seedlings of Avicennia alba, Sonneratia caseolaris and Rhizophora mucronata were transplanted in May 1999, at the end of the hot-dry period. In each plot of both stations, 30 seedlings of each species were transplanted with $2 \mathrm{~m} \times 2 \mathrm{~m}$ spacing. These transplanted seedlings were in the post-cotyledonary phase, during which their survival appears to be largely resource dependent, i.e. independent of nutritional support from the parent (Clarke 1995). The seedlings of A. alba and S. caseolaris were obtained by carefully shoveling up newly established natural seedlings in an adjacent area, while the seedlings of $R$. mucronata were collected under

Table 1. Densities (ind. per $100 \mathrm{~m}^{2}$ ) of neighboring plants existing in the low-, medium- and high-density plots in 2 stations in Pak Phanang Bay. Mangrove plants were classified as seedlings $(<1.5 \mathrm{~m})$, saplings (between 1.5 and $2.5 \mathrm{~m}$ ) or trees $(>2.5 \mathrm{~m})$

\begin{tabular}{|llccr|}
\hline Station & Plot & Seedling & Sapling & Tree \\
\hline Pak Kwang & Low & 97 & 5 & 2 \\
& Medium & 253 & 24 & 13 \\
& High & 389 & 76 & 18 \\
Ai Ho & Low & 68 & 3 & 1 \\
& Medium & 282 & 26 & 11 \\
& High & 338 & 41 & 24 \\
\hline
\end{tabular}

mature trees upstream. The transplanted seedlings were tagged after planting and recovered after a month. We then measured the height and number of internodes on the main stem and repeated these measurements at approximately 3 mo intervals until the plants were more than 1 yr old (September 2000). However, due to the very high monsoon water levels in December 1999 to February 2000 the still submerged Rhizophora and Avicennia spp. seedlings could not be monitored. Only $S$. caseolaris seedlings, which had grown fast enough to reach the water surface, were monitored during that time. Since there were slight differences in initial seedling sizes (with a mean height of 36, 37 and $16 \mathrm{~cm}$ for Avicennia, Rhizophora and Sonneratia spp., respectively), data on seedling height were transformed into relative growth rates $\left(\mathrm{RGR}_{\mathrm{H}}\right)$ (Hunt 1982) prior to analyses. At each visit we also recorded the number of surviving seedlings and analyzed seedling survival using a factorial GLM. Since growth was measured on the same experimental units (i.e. the seedlings) a repeated-measures design was used to properly separate effects of time from treatment in ANOVA (Potvin et al. 1990).

\section{RESULTS}

\section{Water movement}

There was a significant difference in clod card dissolution between the 2 stations ( $p<0.001$; Table 2$)$. Average clod card weight loss per day at Ai Ho Canal $\left(3.78 \pm 0.08 \mathrm{~g} \mathrm{~d}^{-1}\right)$ was somewhat higher than at Pak 
Table 2. Three-way ANOVA examining the effects of stations, neighboring plant densities (plots) and seasons (months) on clod card weight loss $\left(\mathrm{g} \mathrm{d}^{-1}\right)$. Presented are $\mathrm{df}, \mathrm{SS}$, the percentage of variance explained (factor SS/total SS $\times 100$ ) and the level of significance $(p)$

\begin{tabular}{|lrrrc|}
\hline Factors & df & SS & \% variance & $p$ \\
\hline Station & 1 & 31 & 1 & 0.000 \\
Plot & 2 & 324 & 8 & 0.000 \\
Month & 6 & 2905 & 73 & 0.000 \\
Station $\times$ plot & 2 & 34 & 1 & 0.000 \\
Station $\times$ month & 6 & 39 & 1 & 0.000 \\
Plot $\times$ month & 12 & 104 & 2 & 0.000 \\
Station $\times$ plot $\times$ month & 12 & 35 & 1 & 0.000 \\
Residual & 1147 & 513 & 13 & \\
Total & 1188 & 4002 & 100 & \\
\hline
\end{tabular}

while the difference in neighboring plant density and the interaction between species and neighboring plant density explained 11 and $13 \%$ of the total variation, respectively.

Survival curves of Avicennia and Sonneratia spp. were comparatively similar but very different from those of Rhizophora sp. (Fig. 4). The numbers of surviving seedlings of the first 2 species declined throughout the experimental period, whereas those of $R$. mucronata remained fairly constant until after the monsoon season, when mortality was particularly apparent in the low-density plot at Ai Ho. In A. alba, mortality was spread evenly over the whole period, while $S$. caseolaris experienced 2 periods of high mortality (June to September

Kwang Canal $\left(3.46 \pm 0.07 \mathrm{~g} \mathrm{~d}^{-1}\right)$. Clod card dissolution rates were also significantly different between plots of different neighboring plant densities and between seasons ( $p<0.001$; Table 2 ). The plots with the lowest density had the highest clod card dissolution rates $(4.38 \pm$ $0.10 \mathrm{~g} \mathrm{~d}^{-1}$ ), while those with the highest density had the lowest $\left(3.16 \pm 0.09 \mathrm{~g} \mathrm{~d}^{-1}\right)$. In general, most of the variation $(73 \%)$ was accounted for by the seasonality term (Table 2), with the lowest clod card weight loss in July 1998 and the highest in October 1998 (Fig. 3), a pattern coupled with the monsoon period (cf. Fig. 2). Also, the lower maximum clod card dissolution rates in November 1999, compared to those of October 1998 (cf. Fig. 3), coincided with lower rainfall in that period. The largerscale exposure effect (stations) accounted for only $1 \%$ of total variance, while the smaller-scale exposure effect (neighboring plant density) contributed $8 \%$.

The DF was subsequently calculated but only from January 1999 onward, due to loss of control clod card boxes for the first 3 measurements. Average DF was highest at the most exposed plot of $\mathrm{Ai}$ Ho Canal in April 2000 (9.24 \pm 0.10$)$ and lowest at the densest plot of Ai Ho Canal in May 1999 $(2.20 \pm 0.03)$.

\section{Seedling survival}

Significant differences in seedling survival were detected between species and at the smaller-scale exposure (plot) level but not at the larger-scale exposure (station) level (Table 3). Most of the variation (47\%) was explained by the difference in species, 1999 and November 1999 to February 2000; Fig. 4). Also, Avicennia and Sonneratia spp. seedlings had higher survival rates in the plots with low plant density, i.e. at high exposure. In contrast, $R$. mucronata seedlings survived much better in the less exposed,
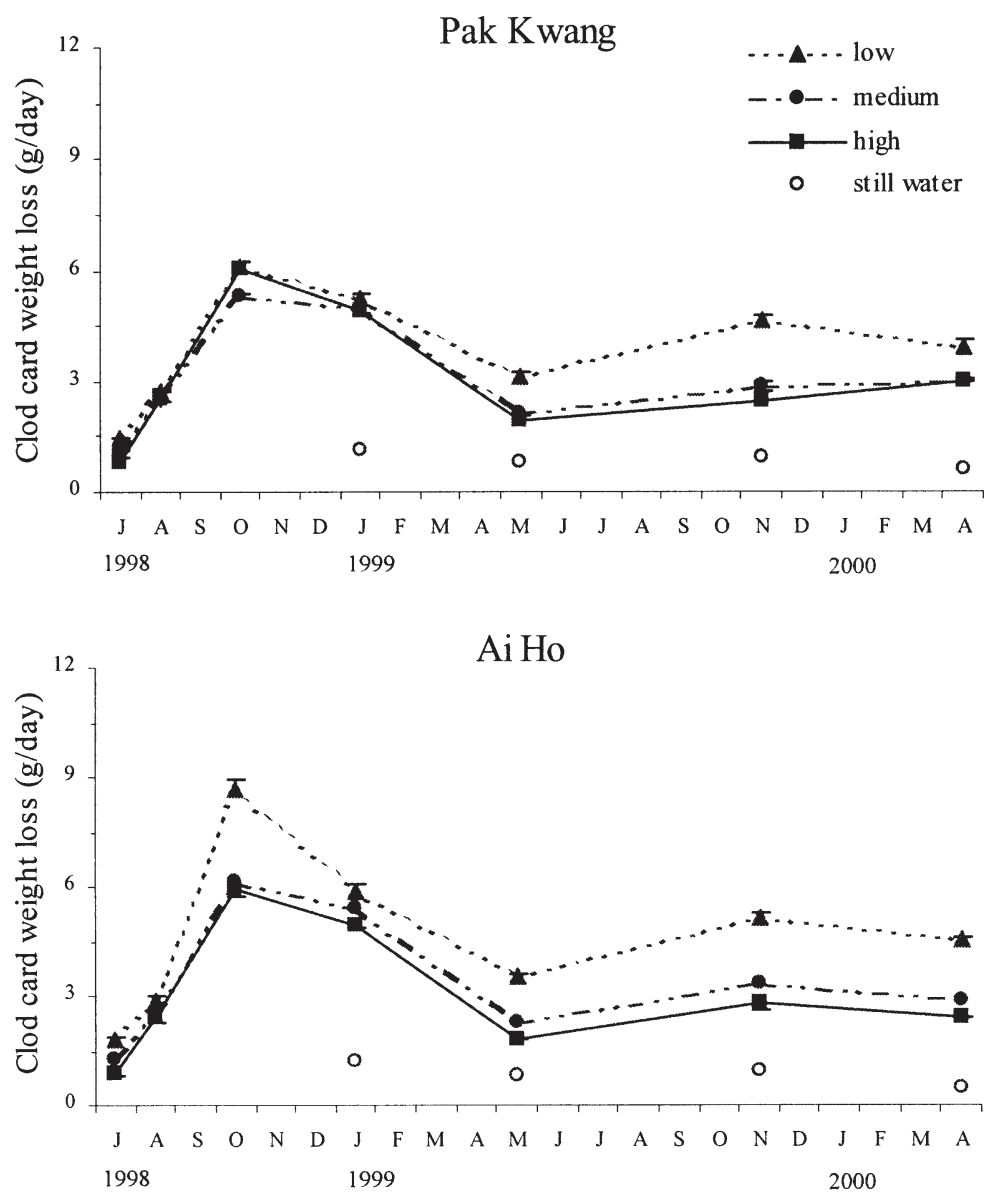

Fig. 3. Seasonal pattern of clod card dissolution $\left(\mathrm{g} \mathrm{d}^{-1}\right)$ at 3 plots of different neighboring tree density (low, medium and high) and in still water of the 2 stations. Presented are means \pm standard error (SE) 
denser plots (Fig. 4). After a 1 yr cycle, between 8 and $40 \%$ of the $S$. caseolaris had survived, with survival being highest in the outermost low-density plots (Table 4). Likewise, A. alba had the highest survival at the lowest density of neighboring trees, with the mortality rate ranging between 30 and $85 \%$. In $R$. mucronata, mortality rates after $1 \mathrm{yr}$ were relatively low in the medium and high plant-density plots (13 and 15\%), but comparatively high in the low plantdensity plots (43\%, Table 4).

Table 3. Three-way ANOVA examining the effects of species, stations and neighboring plant densities (plots) on seedling survival

\begin{tabular}{|lrrrr|}
\hline Factors & df & SS & \% variance & p \\
\hline Station & 1 & 32 & 1 & 0.394 \\
Plot & 2 & 518 & 11 & 0.006 \\
Species & 2 & 2186 & 47 & 0.000 \\
Station $\times$ plot & 2 & 6 & $<1$ & 0.948 \\
Station $\times$ species & 2 & 7 & $<1$ & 0.919 \\
Plot $\times$ species & 4 & 599 & 13 & 0.019 \\
Station $\times$ plot $\times$ species & 4 & 35 & 1 & 0.934 \\
Residual & 30 & 1291 & 28 & \\
Total & 47 & 4613 & 100 & \\
& & & & \\
\hline
\end{tabular}

Pak Kwang

Ai Ho
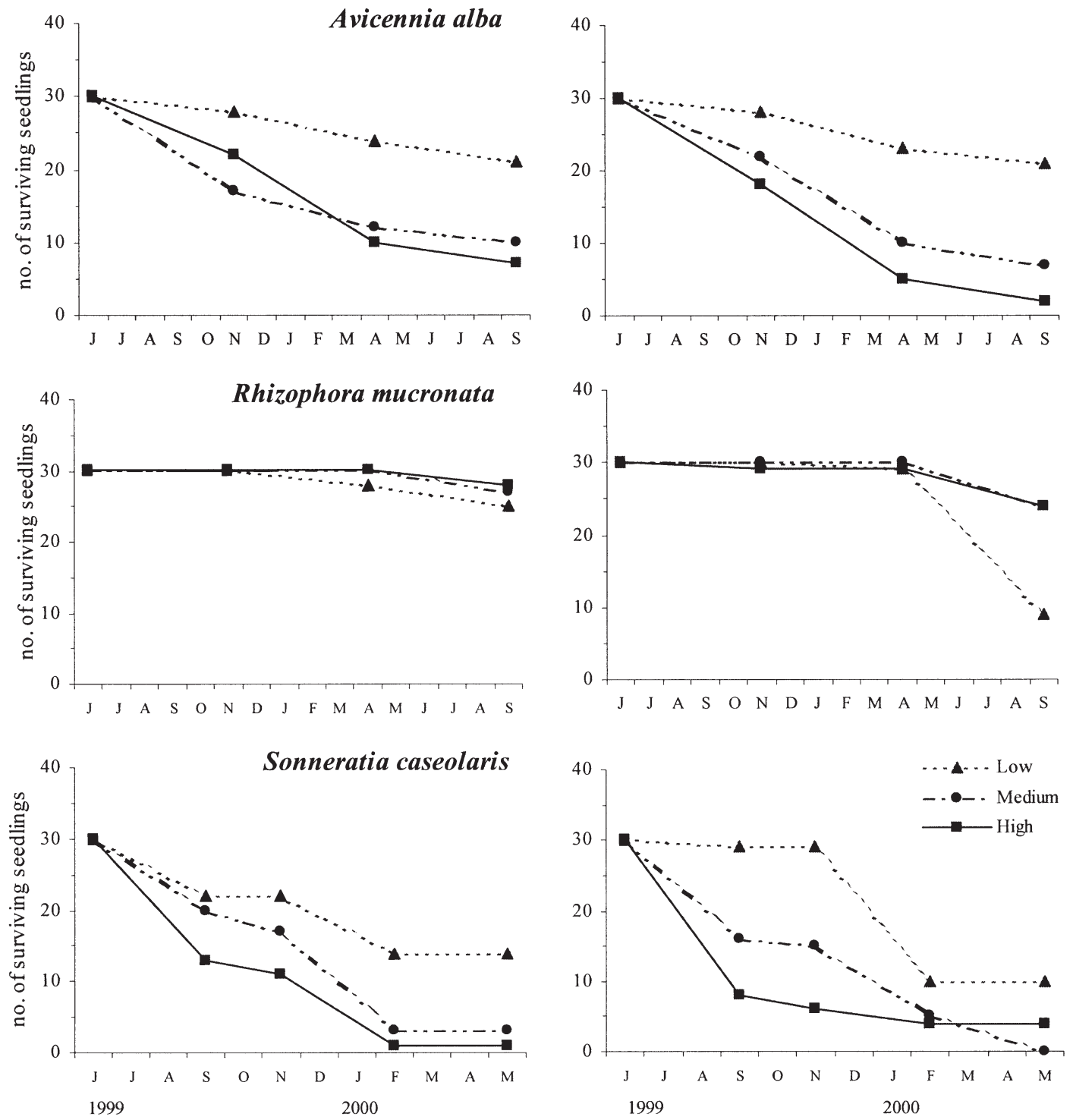

Fig. 4. Survival curves of Avicennia alba, Rhizophora mucronata and Sonneratia caseolaris seedlings at 3 plots of different neighboring tree density at Pak Kwang and Ai Ho canals 
Table 4. Mortality rate (\%) after 1 yr of the 3 mangrove species in the plots of increasing neighboring plant density. Presented are means \pm standard error (SE) calculated from both stations

\begin{tabular}{|llll|}
\hline \multirow{2}{*}{ Species } & \multicolumn{3}{c|}{ Neighboring plant density } \\
& Low & Medium & High \\
\hline Avicennia alba & $30.0 \pm 0.0$ & $71.7 \pm 5.0$ & $85.0 \pm 8.3$ \\
Rhizophora mucronata & $43.3 \pm 26.7$ & $15.0 \pm 5.0$ & $13.3 \pm 6.7$ \\
Sonneratia caseolaris & $60.0 \pm 6.7$ & $95.0 \pm 5.0$ & $91.7 \pm 5.0$ \\
\hline
\end{tabular}

\section{Seedling height}

First, the data of all 3 species were combined and analyzed using repeated-measures GLM to examine the effect on seedling growth of the factors time, species, stations and plots of different neighboring plant density. We found that the repeated-measures factor (time) and its interaction with stations, and its interaction with species and plots were all significant ( $p<0.05)$. We also found highly significant differences in $\mathrm{RGR}_{\mathrm{H}}$ between species and between the 2 stations ( $p<0.001$; Table 5), and slight significant differences between plots of contrasting density ( $p<0.05$; Table 5). The Sonneratia caseolaris seedlings had the highest $\mathrm{RGR}_{\mathrm{H}}$, while those of Avicennia alba had the lowest (Table 6). Overall, $\mathrm{RGR}_{\mathrm{H}}$ declined with increasing age of the seedlings (Fig. 5).

Subsequently, the data of each species were analyzed separately in order to examine the effect of the larger (station) and smaller (plot) scales of exposure on each species individually. The significant difference in $\mathrm{RGR}_{\mathrm{H}}$ was detected between the 2 stations for all species $(\mathrm{p}<0.05$; Table 5$)$. The factor plots were not significant for Avicennia alba and barely significant for Sonneratia caseolaris ( $\mathrm{p}=0.052$; Table 4) but highly significant for Rhizophora mucronata ( $\mathrm{p}<0.001$; Table 5). $\mathrm{RGR}_{\mathrm{H}}$ of Avicennia and Sonneratia spp. seedlings at Ai Ho Canal were substantially higher than at Pak Kwang Canal (Table 6). Similar to seedling survival, $R$. mucronata seedlings exhibited a significantly higher $\mathrm{RGR}_{\mathrm{H}}$ in the high-density plot $(0.753 \pm$ $0.058 \mathrm{~mm} \mathrm{~cm}^{-1} \mathrm{mo}^{-1}$ ) than in the low-density plot $\left(0.715 \pm 0.058 \mathrm{~mm} \mathrm{~cm}^{-1} \mathrm{mo}^{-1}\right)$.

\section{Number of internodes produced}

Monthly internode production was analyzed in the same way as $\mathrm{RGR}_{\mathrm{H}}$. We found that the effect of time (repeated measures) and its interaction with stations were not significant, while its interaction with species and with plots was significant $(\mathrm{p}<0.05)$. The number of internodes produced per month was significantly different between species, between plots and between the 2 stations $(p<0.001$; Table 7$)$. The interaction between stations and species, as well as stations and plots, was highly significant ( $p<0.001$; Table 7 ) while the interaction between plots and species was just significant ( $\mathrm{p}<$ 0.05; Table 7). As with $\mathrm{RGR}_{\mathrm{H}}$, a significant difference in monthly internode production between the 2 stations was detected for Avicennia and Sonneratia spp. ( $\mathrm{p}<$ 0.05; Table 7) but not for Rhizophora mucronata. In addition, the factor plots were highly significant for $R$. mucronata ( $\mathrm{p}<$ 0.001 ; Table 7) but were just significant for Sonneratia and Avicennia spp. ( $p<0.05$; Table 7). The interaction between stations and plots was significant for all 3 species ( $\mathrm{p}<$ 0.05). In accordance with height increment, the $S$. caseolaris seedlings had the highest monthly internode production, while $R$. mucronata had the lowest, and the internode production of Avicennia and Sonneratia spp. seedlings at Ai Ho Canal were substantially higher than at Pak Kwang Canal (Table 6, Fig. 6). R. mucronata seedlings had a higher internode production in the lower neighboring plantdensity plot $(0.658 \pm 0.017,0.539 \pm$ 0.014 and $0.532 \pm 0.015$ internode $\mathrm{mo}^{-1}$ at the plots of low, medium and high density, respectively). 
Table 6. Overall $\mathrm{RGR}_{\mathrm{H}}$ and number of internodes produced of the 3 mangrove species at Pak Kwang and Ai Ho Canals. Presented are means \pm SE

\begin{tabular}{|lcrrr|}
\hline Species & \multicolumn{2}{c|}{$\begin{array}{c}\mathrm{RGR}_{\mathrm{H}} \\
\left(\mathrm{mm} \mathrm{cm}^{-1} \mathrm{mo}^{-1}\right)\end{array}$} & \multicolumn{2}{c|}{$\begin{array}{c}\text { Internode } \\
\text { (internode mo }\end{array}$} \\
& Pak Kwang & Ai Ho & Pak Kwang & Ai Ho \\
\hline Avicennia alba & $0.436 \pm 0.017$ & $0.777 \pm 0.033$ & $0.649 \pm 0.028$ & $1.011 \pm 0.041$ \\
Rhizophora mucronata & $0.720 \pm 0.036$ & $0.743 \pm 0.035$ & $0.568 \pm 0.013$ & $0.579 \pm 0.013$ \\
Sonneratia caseolaris & $1.395 \pm 0.108$ & $2.158 \pm 0.139$ & $1.855 \pm 0.096$ & $2.918 \pm 0.138$ \\
& & & & \\
\hline
\end{tabular}

Pak Kwang
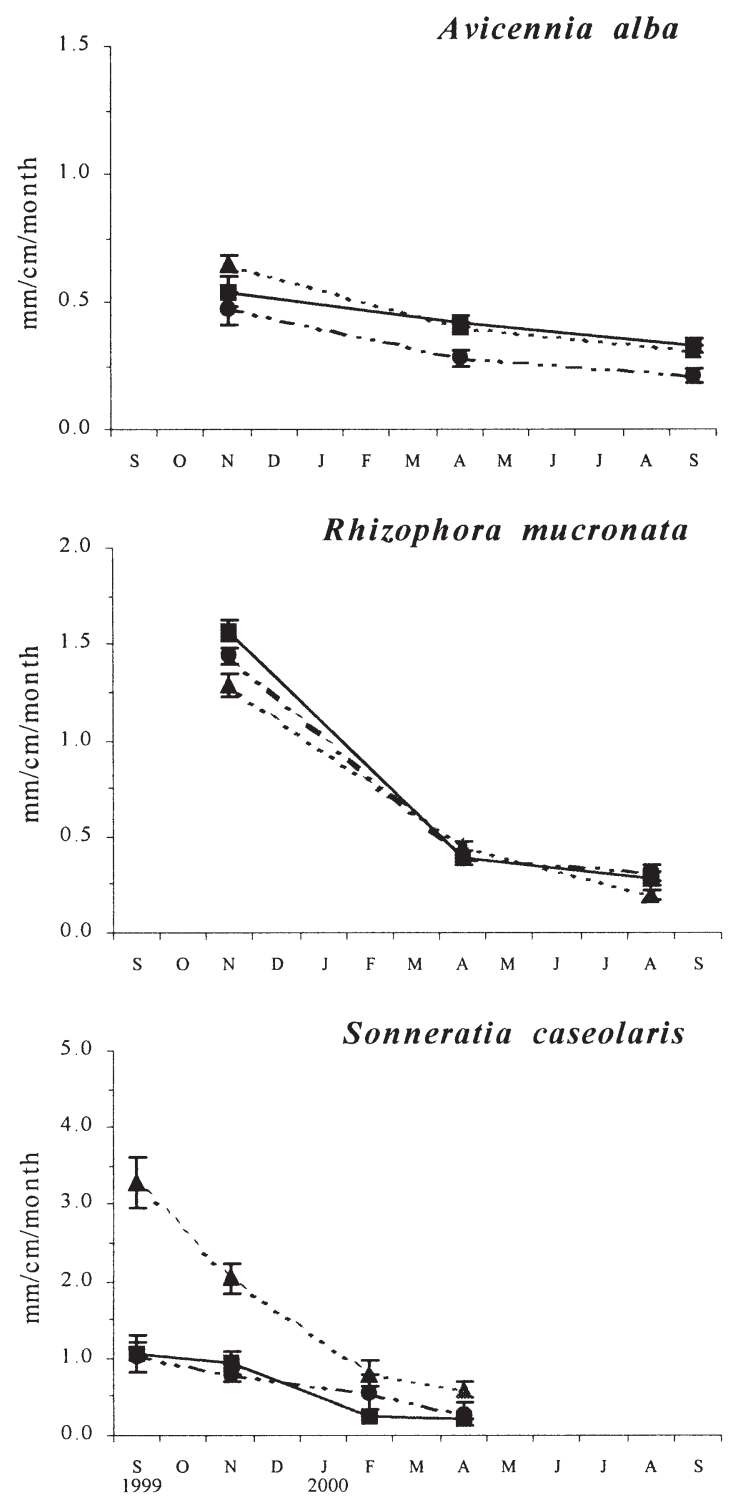

Ai Ho
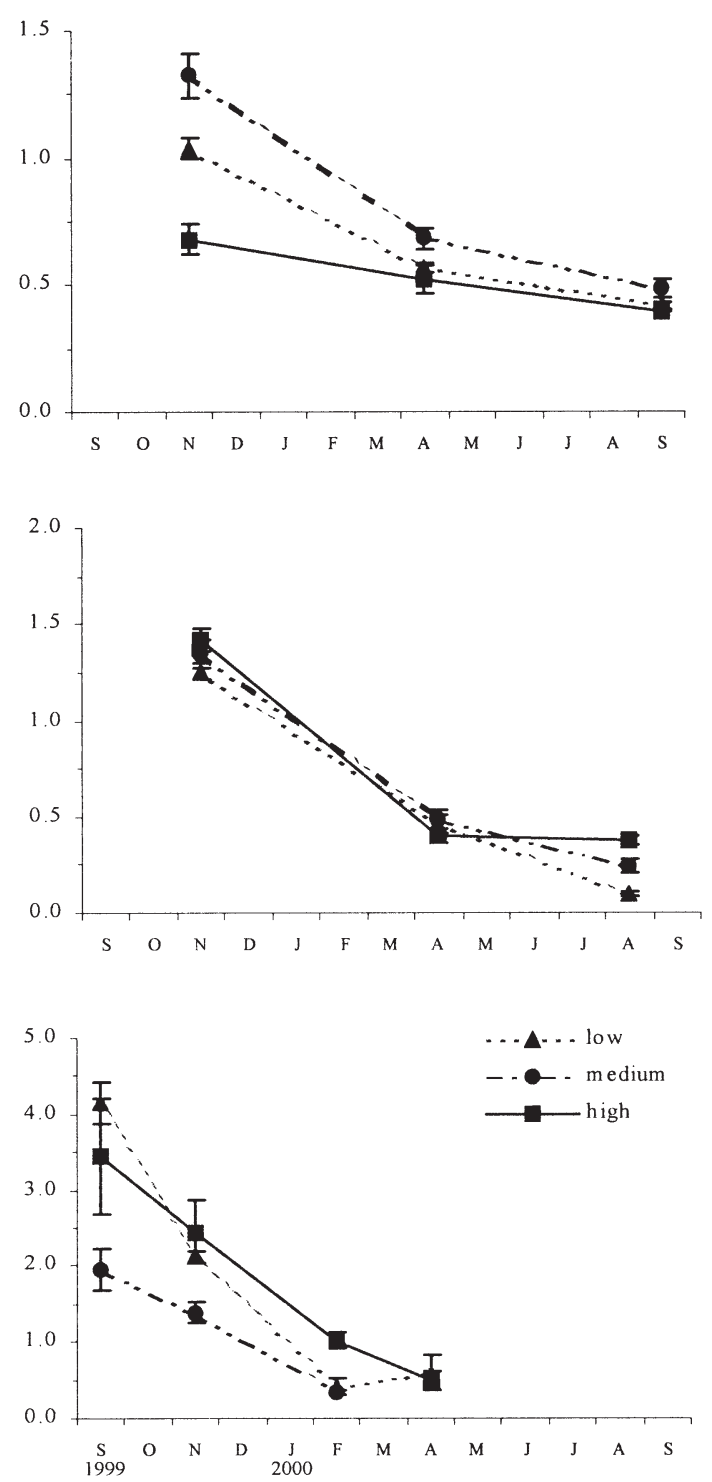

Fig. 5. Relative growth rate expressed in height $\left(\mathrm{mm} \mathrm{cm}^{-1} \mathrm{mo}^{-1}\right)$ of Avicennia alba, Rhizophora mucronata and Sonneratia caseolaris seedlings at 3 plots of different neighboring tree density at Pak Kwang and Ai Ho Canals. Presented are means \pm SE. The graphs of each species have a different scale on the $y$-axis 
Table 7. Result of repeated-measures GLM examining the effects of species, stations and neighboring plant densities (plots) on number of internodes produced per month for all 3 species and each species separately. The repeated-measures factor (time) was not significant ( $p=0.121)$, nor was its interaction with stations $(p=0.288)$, while its interaction with species and its interaction with density were significant $(\mathrm{p}<0.05)$

\begin{tabular}{|c|c|c|c|c|c|c|}
\hline \multirow[t]{2}{*}{ Factors } & \multicolumn{3}{|c|}{ All species } & \multicolumn{3}{|c|}{ Avicennia alba } \\
\hline & df & SS & $\mathrm{p}$ & $\mathrm{df}$ & SS & $\mathrm{p}$ \\
\hline Species & 2 & 84.406 & 0.000 & & & \\
\hline Station & 1 & 25.557 & 0.000 & 1 & 4.242 & 0.000 \\
\hline Plot & 2 & 16.958 & 0.000 & 2 & 0.796 & 0.016 \\
\hline Station $\times$ plot & 2 & 12.248 & 0.000 & 2 & 0.598 & 0.043 \\
\hline Station $\times$ species & 2 & 22.241 & 0.000 & & & \\
\hline Plot $\times$ species & 4 & 13.667 & 0.014 & & & \\
\hline Station $\times$ plot $\times$ species & 4 & 18.259 & 0.000 & & & \\
\hline Within + residual & 222 & 62.010 & & 64 & 5.769 & \\
\hline \multirow[t]{2}{*}{ Factors } & \multicolumn{3}{|c|}{ Rhizophora mucronata } & \multicolumn{3}{|c|}{ Sonneratia caseolaris } \\
\hline & df & SS & $\mathrm{p}$ & df & SS & $\mathrm{p}$ \\
\hline Station & 1 & 0.005 & 0.604 & 1 & 21.420 & 0.003 \\
\hline Plot & 2 & 0.625 & 0.000 & 2 & 15.591 & 0.033 \\
\hline Station $\times$ plot & 2 & 0.361 & 0.000 & 2 & 22.971 & 0.002 \\
\hline Within + residual & 131 & 2.518 & & 27 & 54.503 & \\
\hline
\end{tabular}

\section{DISCUSSION}

As confirmed by our results, water movement varied between the 2 stations and between plots of different existing tree density, with most of the variation being seasonal. Water movement was higher in the monsoon season of October to January than in the other months of the year. The variation of shelter at the smaller (plot) scale was considerably higher than at the larger (station) scale. Shelter increased gradually from the mangrove forest edge to the interior, similar to patterns found by others (Leonard \& Luther 1995). We found that water movement at the bottom of this mangrovefringed bay was relatively low as $<5 \%$ of the initial weight of the deployed clod cards dissolved per day. The DF values calculated from our data ranged between 2 and 9, which is considerably less than the ranges reported for tropical intertidal seagrass beds (10 to 15, Erftemeijer \& Herman 1994) and a coral reef flat and lagoon (5 to 25, Jokiel \& Morrissey 1993). This is not unexpected, given the fine texture of sediment of Pak Phanang Bay (Kamp-Nielsen et al. 2002), indicative of low sediment erosion rates and low velocities reported for mangrove systems elsewhere (Wolanski 1992).

Apparently, the initial size of the seedlings was large enough to prevent them being attacked by crabs. Therefore, none of them were damaged by this sort of predator. In addition, only a few crabs were observed in the area. Seedling survival differed significantly be- tween the 3 species and with increasing tree density between plots Seedling mortality was spread equally over the year in Avicennia alba, which was not the case in the other 2 species. In Sonneratia caseolaris, 2 periods of increased mortality were observed, which coincided with heavy rainfall, to which its smaller seedlings may be more sensitive than those of the other species. After $1 \mathrm{yr}$, the mortality rate in the low plant-density plots was highest in Rhizophora mucronata but lowest in Avicennia and Sonneratia spp. (Table 4). The observed maximum survival in the most exposed and open plots of both Avicennia and Sonneratia spp. is in agreement with their role as pioneer species (Clough 1982, Tomlinson 1986, Panapitukkul et al. 1998). Our observation suggested that the main cause of high mortality of $R$. mucronata in the most exposed plots was uprooting by waves or drifting objects colliding against the lengthy, rigid seedlings. The higher mortality in the exposed, mangrove front area may be a factor explaining the later appearance along the successional series of this species (Tomlinson 1986).

Seedling growth varied strongly between species. Growth of Avicennia and Sonneratia spp. differed significantly between the inner and outer sites of the bay. A. alba had a higher seedling growth at the exposed site of Ai Ho, near natural stands, than at the inner site of Pak Kwang (Figs. $5 \&$ 6, Table 6). Growth of S. caseolaris followed the same pattern but its survival was higher at Pak Kwang, near natural stands, than at Ai Ho. Growth of Rhizophora mucronata was not significantly different between the 2 bay sites but $R R_{H}$ increased with increasing neighboring vegetation densities. The seedlings of $S$. caseolaris had the highest growth in terms of both height increase and production of internodes along the main stem. We found the annual number of internodes produced for Sonneratia, Avicennia and Rhizophora spp. to be $30.3 \pm 1.7,13.2 \pm$ 0.3 and $6.5 \pm 0.2$, respectively, which did not differ substantially from those of naturally established seedlings $(28.8 \pm 2.1$ and $17.6 \pm 0.8$ for $S$. caseolaris and A. alba, Panapitukkul et al. 1998, Duarte et al. 1999; $6.1 \pm 0.3$ for R. mucronata, Duarte et al. 1999, Thampanya et al. unpubl.). The observed decline in relative seedling growth with age is a common phenomenon in terrestrial plants ('ontogenetic drift', Van Andel \& Jager 1981). 
Pak Kwang
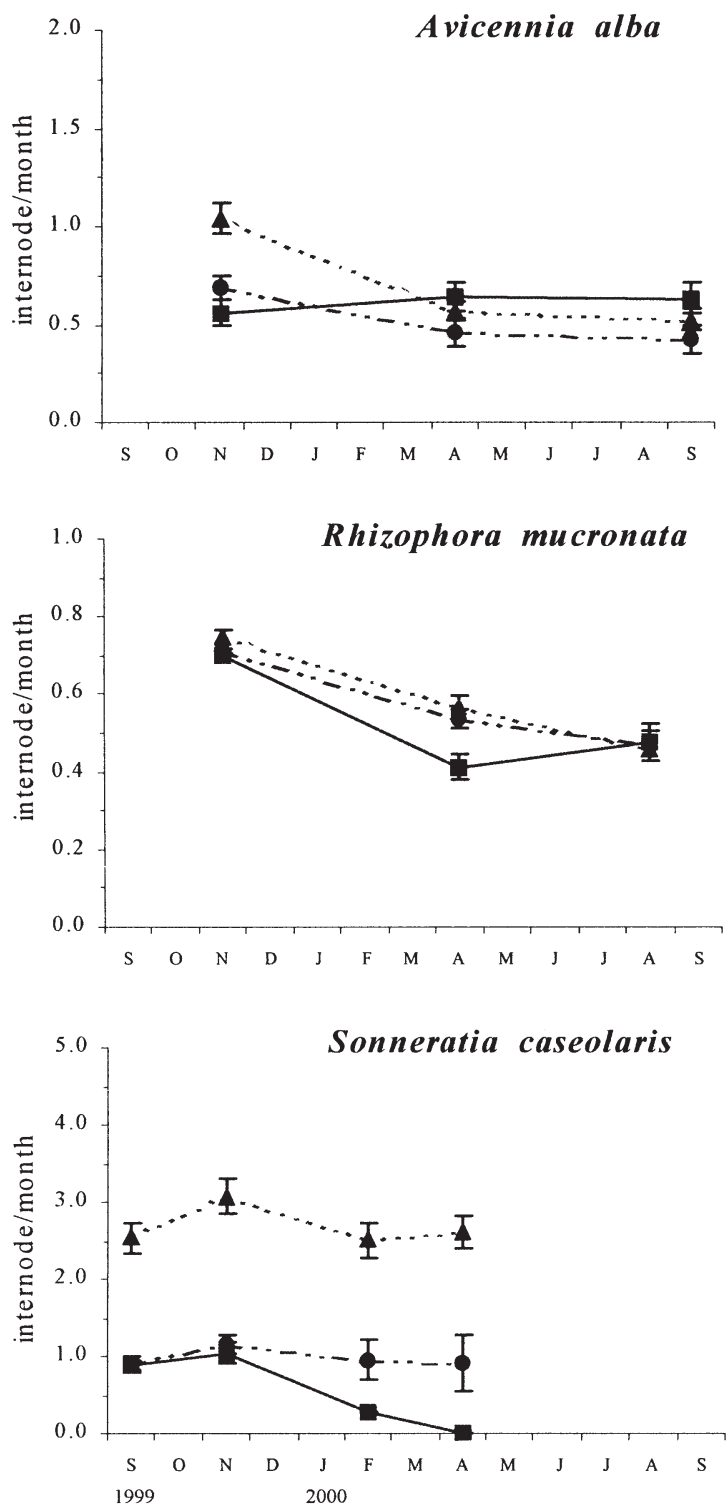

Ai Ho
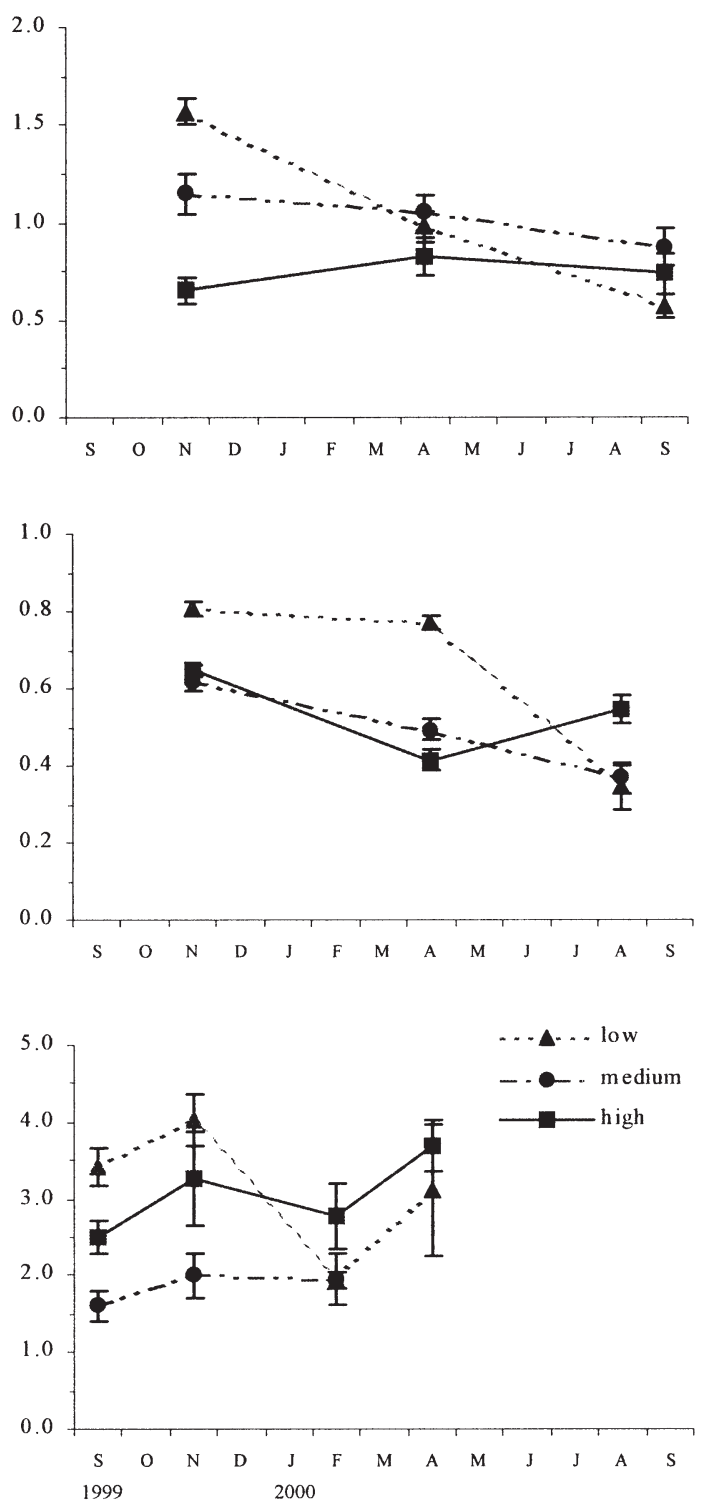

Fig. 6. Number of internodes produced (internode $\mathrm{mo}^{-1}$ ) of Avicennia alba, Rhizophora mucronata and Sonneratia caseolaris seedlings at 3 plots of different neighboring tree density at Pak Kwang and Ai Ho Canals. Presented are means \pm SE. The graphs of each species have a different scale on the $y$-axis

Our results confirm the higher survival of Avicennia alba and Sonneratia caseolaris at the outer, colonizing front of the mangrove forest and provide an explanation for their role as pioneer species in the Pak Phanang Bay mangrove area (Panapitukkul et al. 1998). These species appear to be affected negatively by density of adult plants. These effects may be derived from the shading associated with increasing tree density. Rhizophora mucronata shows an opposite pattern, with the best seedling performance associated with denser stands, in agreement with their succes- sional role, as climax species in natural SE Asian mangrove forests. The first 2 species are also capable of establishing themselves on the open mudflat, so that mangrove rehabilitation is probably not needed if natural colonization by these species is not prevented. In addition, the cost for replanting mangrove with $R$ hizophora sp. is relatively high: in Thailand, this was estimated at \$US500 ha-1 (Plathong 1998). However, intensive human exploitation activities (such as fishing by push net and trawler) and traffic across the mudflat by local fishing boats are major sources of disturbance, 
dislodging numerous mangrove seedlings. The creation of temporary reserved areas excluding these activities may be sufficient to enable natural colonization. If the replanting of economical species such as Rhizophora is required, areas with some existing plants are suggested as the most suitable for planting.

In summary, our results demonstrate contrasting effects of exposure and neighboring plant density on the performance of the seedlings of the 3 most important species in the mangrove forest studied. These effects are consistent with the role of the species in the successional series, suggesting that exposure and density are important determinants of mangrove species succession. The results obtained may, in addition, provide a basis for the selection of suitable target species for afforestation programs in different mangrove areas.

Acknowledgements. The authors are grateful to the Coastal Resources Institute and the Faculty of Natural Resources of the Prince of Songkla University, in general, and to Dr. Somsak Boromthanarat, in particular, for giving useful suggestions and providing all research facilities. We thank Nawee Noon-anand, Chamnan Worachina, Phollawat Saijung and the fishermen at Pak Phanang West village for their friendly assistance in field data collection. We are also grateful to Prof. Patrick Denny for critically reading the manuscript. This study is funded by the Netherlands Foundation for the Advancement of Tropical Research, WOTRO project WB 84-412.

\section{LITERATURE CITED}

Clarke PJ (1995) The population dynamics of the mangrove Avicennia marina; demographic synthesis and predictive modelling. Hydrobiologia 295:83-88

Clarke PJ, Allaway WG (1993) The regeneration niche of the grey mangrove (Avicennia marina): effects of salinity, light and sediment factors on establishment, growth and survival in the field. Oecologia 93:548-556

Clough BF (1982) Mangrove ecosystems in Australia. Australian Institute of Marine Science and Australian National University Press, Canberra

Delgado P, Jiménez JA, Justice D (1999) Population dynamics of mangrove Avicennia bicolor on the Pacific coast of Costa Rica. Wetlands Ecol Manage 7:113-120

Doty MS (1971) Measurement of water movement in reference to benthic algal growth. Bot Mar 14:32-35

Duarte CM, Thampanya U, Terrados J, Geertz-Hansen O, Fortes MD (1999) The determination of the age and growth of SE Asian mangrove seedlings from internodal counts. Mangroves Salt Marshes 3:251-257

Erftemeijer PLA, Herman PMJ (1994) Seasonal changes in

Editorial responsibility: Otto Kinne (Editor),

Oldendorf/Luhe, Germany environmental variables, biomass, production and nutrient contents in two contrasting tropical intertidal seagrass beds in South Sulawesi, Indonesia. Oecologia 99:45-59

Field CD (1995) Journey amongst mangroves. International Society for Mangrove Ecosystems, Okinawa

Havanond S (1995) Re-afforestation of mangrove forests in Thailand. In: Khemnark C (ed) Proceeding of the ECOTONE IV Meeting on Ecology and Management of Mangrove Restoration and Regeneration in East and Southeast Asia. Kasetsart University, Bangkok, p 203-216

Hunt R (1982) Plant growth curves: the functional approach to plant growth analysis. Edward Arnold, London

Hutchings P, Saenger P (1987) Ecology of mangroves. University of Queensland Press, St Lucia

JICA (1987) Basic design study report on the project for constructing the Nakhon Si Thammarat fishing port. Japan International Cooperation Agency (JICA), Tokyo

Jokiel PL, Morrissey JI (1993) Water motion on coral reefs; evaluation of the 'clod card' technique. Mar Ecol Prog Ser 93:175-181

Kamp-Nielsen L, Vermaat JE, Wesseling I, Borum J, GeertzHansen (2002) Sediment properties along gradients of siltation in South-East Asia. Estuar Coast Shelf Sci 54: $127-137$

Leonard LA, Luther ME (1995) Flow hydrodynamics in tidal marsh canopies. Limnol Oceanogr 40:1474-1484

Panapitukkul N, Duarte CM, Thampanya U, Terrados J, Keowvongsri P, Geertz-Hansen O, Srichai N, Boromthanarat S (1998) Mangrove colonization: mangrove progression over the growing Pak Phanang (SE Thailand) mud flat. Estuar Coast Shelf Sci 47:51-56

Petticrew EL, Kalff J (1991) Calibration of a gypsum source for freshwater flow measurements. Can J Fish Aquat Sci 48: $1244-1249$

Plathong J (1998) Status of mangrove forest in southern Thailand. Wetlands International-Thailand Programme/PSU, Publication No 5

Porter ET, Sanford LP, Suttles SE (2000) Gypsum dissolution is not a universal integrator of 'water motion'. Limnol Oceanogr 45:145-158

Potvin CP, Lechowicz MJ, Tardif S (1990) The statistical analysis of ecophysiological response curves obtained from experiments involving repeated measures. Ecology 71:1389-1400

Silvertown JW (1982) Introduction to plant population ecology. Longman Group Limited, New York

Tomlinson PB (1986) The botany of mangroves. Cambridge University Press, Cambridge

Tomlinson PB (2000) Systematic and functional anatomy of seedlings in mangrove Rhizophoraceae: vivipary explained? Bot J Linn Soc 134:215-231

Van Andel J, Jager JC (1981) Analysis of growth and nutrition of 6 plant species of woodland clearings. J Ecol 69: 871-882

Wolanski E (1992) Hydrodynamics of mangrove swamps and their coastal waters. Hydrobiologia 247:141-161

Submitted: June 1, 2001; Accepted: March 19, 2002

Proofs received from author(s): June 21, 2002 